\title{
التنظيم القانوني لحقوق الطفل في التشريعات الفلسطينية
}

\author{
أحمد عبد الحكبم شههاب \\ محامي، دكتوراه في القانون العام والقضاء \\ أستاذ القانون العام المساعد بكلية الشريعة والقانون دهن \\ الجامعة الإسلامية بغزة- فلسطين \\ ashehab@iugaza.edu.ps
}


www.refaad.com
المجلة الدولية للدراسات القانونية والفقهية المقارنة

International Journal of Legal and Comparative Jurisprudence Studies (LCJS)

Journal Homepage: https://www.refaad.com/views/LCJS/Home.aspx

ISSN: 2708-6607(Online) 2708-6593(Print)

\title{
التنظيم القانوني لحقوق الطفل في التشريعات الفلسطينية
}

\author{
أحمد عبد الحكيم شهاب \\ محامي، دكتوراه في القانون العام والقضياء
}

أستاذ القانون العام المساعد بكلية الشريعة والقانون- الجامعة الإسلامية بغزة- فلسطين

ashehab@iugaza.edu.ps

DOI: https://doi.org/10.31559/LCJS2021.2.1.1 2021/3/17 2020/10/18 مراجعة البحث: 2021/1/25 قبول البحث البحث:

تهدف الدراسة لتحليل وتقييم التنظيم القانوني لحقوق الطفل في التشريعات الفلسطينية، حيث تسلط الضوء على مدى مواءمة

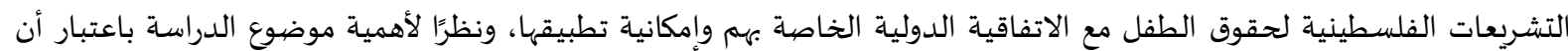

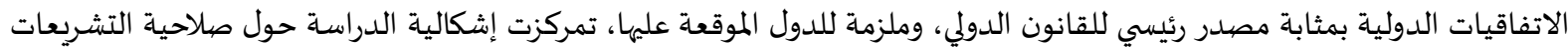

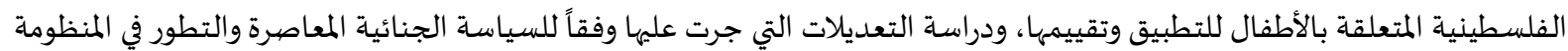
التشريعية العالمية. ولتحقيق هدف الدراسة الرئيسي استخدم الباحث المنهج الوصفي التحليلي، من خلال تحليل النصوص القانونية

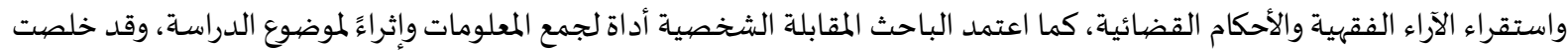

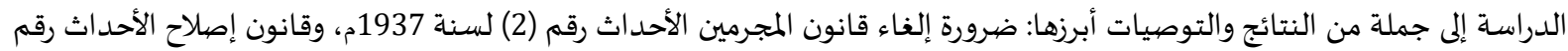

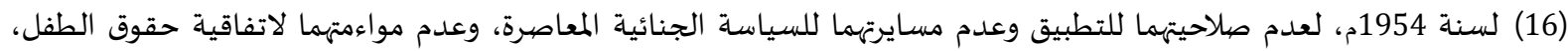

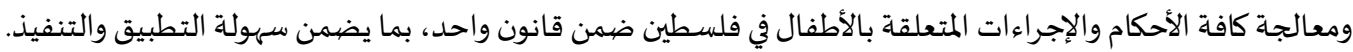
الكلمات المفتاحية: حقوق الطفل؛ تشريعات؛ فلسطين.

مرت المنظومة التشريعية الفلسطينية منذ انتهاء الخلافة العثمانية بمراحل عدة؛ نتيجة لعدم استقرار النظام السياسي في فلسطين، من حيث المرجعية القانونية، والحد المكاني لنفاذ هذه التشريعات.

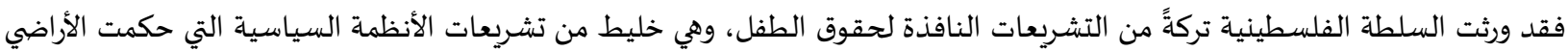

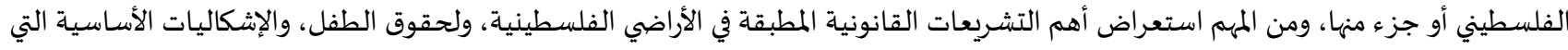
انطوت عليها. ويشمل الإطار القانوني لحقوق الطفل في فلسطين على مجموعة من التشريعات الفلسطينية التي تنص على حقوق الطفل والجوانب الإجرائية،

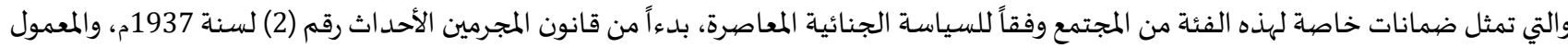
باه في قطاع غزة، وقانون إصلاح الأحداث المعمول باه في الضفة الغربية رقم (16) لسنة 1954م، مروراً بإقرار قانون الطفل الفلسطيني رقم (7) لسنة

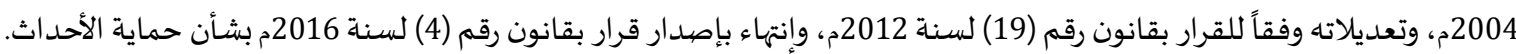


ومما لا شك فياء أن قضية حماية ورعاية الأطفال بفئاتهم المختلفة باتت تأخذ حيزاً كبيراً من الاهتمام سواءً على الصعيد الدولي أو على الصعيد

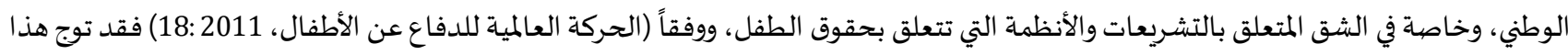

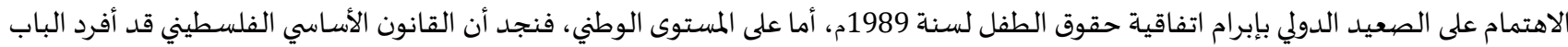

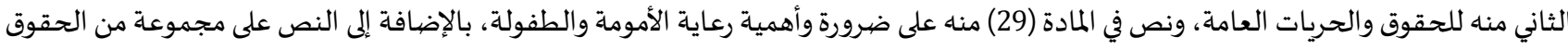

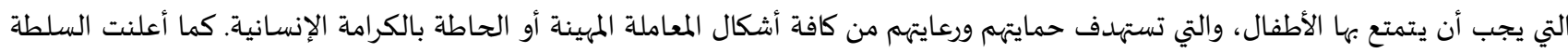
الوطنية الفلسطينية في المادة (10) من القانون الأسساسي الفلسطيني المعدل لعام 2003م على أها تعمل دون إبطاء على الانضمام إلى الإعلانات والمواثيق الإقليمية والدولية التي تحمي حقوق الإنسان. ومما لا شك فياه أن حقوق الأطفال تأتي في مقدمة حقوق الإنسان، كون هذه الفئة بحكم ضعف قوان قواها الفكرية والبدنية بحاجة إلى مزيد من الحماية والرعاية.

$$
\text { أهمية الدراسـة: }
$$

في ظل تعدد التشريعات لحقوق الطفل في القانون الفلسطيني، وأهمية مواءمتها مع اتفاقية حقوق الطفل، باعتبار أن الاتفاقيات الدولية مصدراً رئيسياً للقانون الدولي، وتطبيقاً لمبدأ سمو القانون، تسلط هذه الدراسة على مدى مواءمة التشريعات الفلسطينية لحقوق الطفل مع اتفاقية حقوق

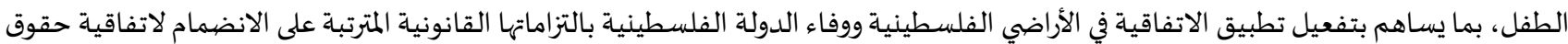
الطفل، ومنع أي تعارض ما بين القانون الدولي والقوانين الوطنية. بحيث تتناول هذه الدراسة بيان التشريعات القانونية المتعلقة بحقوق الأطفال في التشريع الفلسطيني وتقييمها من حيث نقاط القوة والضعف، بالإضافة لدراسة التعديلات التي تمت علهها، ومدى ملاءمة التشريعات الفلسطينية لحقوق الأطفال للتطبيق في الأراضي الفلسطينية.

إشكالية الدراسـة:

تكمن إشكالية في ضرورة البحث في صلاحية التشريعات الفلسطينية المتعلقة بالأطفال للتطبيق وتقييمها، ودراسة التعديلات التي تمت عليها وفقاً

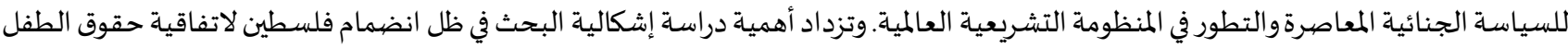
وضرورة مواءمة فلسطين لتشريعاتها الداخلية مع الاتفاقية.

\section{منهجية الدراسـة:}

اعتمد الباحث في دراسته المنهاج الوصفي التحليلي منهجية للبحث، للوصول إلى تحليل النصوص التشريعية المقارنة والأحكام القضائية والآراء

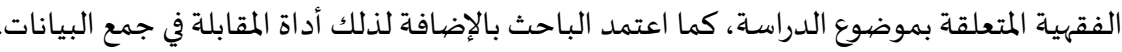

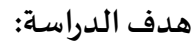

تهدف الدراسة بشكل لتحليل وتقييم التنظيم القانوني لحقوق الطفل في التشريعات الفلسطينية.

$$
\text { تقسيم الدراسـة: }
$$

المبحث الأول: التشريعات المتخصصية بحقوق الطفل في فلسطين. المطلب الأول: قانون المجرمين الأحداث رقم (2) لسنة 1937م. لمبردئ المطلب الثاني: قانون اصلاح الأحداث رقم (16) لسنة 2004م. لماحدئ المطلب الثالث: قانون الطفل الفلسطيني رقم (7) لسنة 2004م. المبحث الثاني: القرارات بقو انين بشأن حقوق الطفل في فلسطين. المطلب الأول: قرار بقانون رقم (19) لسنة 2012م بشأن تعديل قانون الطفوان الطفل الفلسطيني. المطلب الثاني: قرار بقانون رقم (4) لسنة 2016م بشأن حماية الأحداث. 


\section{المبحث الأول: التشريعات الفلسطينية المتخصصية بحقوق الطفل}

نستعرض في هذا الفصل مجموعة التشربعات القانونية الناظمة لحقوق الطفل في فلسطين، والمتمثلة في قانون المجرمين الأحداث رقم (2) لسنة

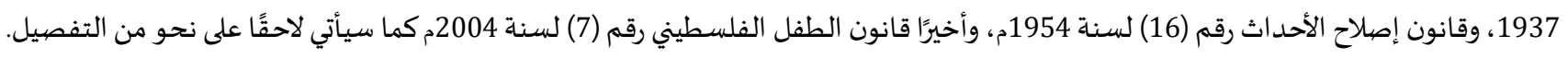

المطلب الأول: قانون المجرمين الأحداث رقم (2) لسنة 1937م:

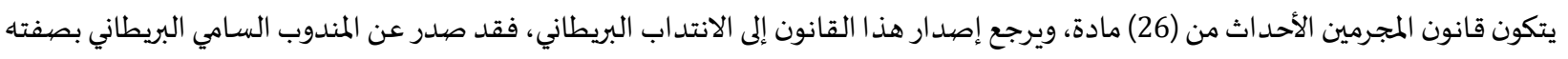

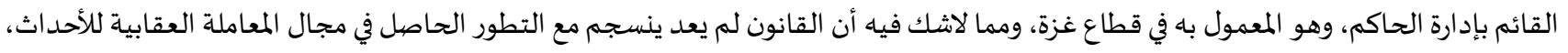

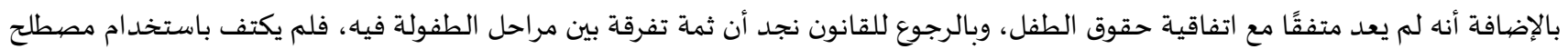

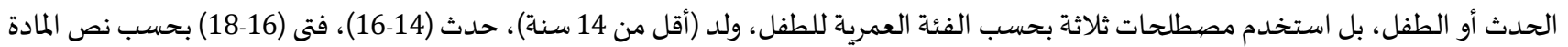

فالمشكلة المتعلقة بالأحداث الجانحين لم يتم معالجتها، فما زال قانون المجرمين الأحداث رقم (2) لسنة 1937م ساري المفعول في قطاع غزةة، ومن

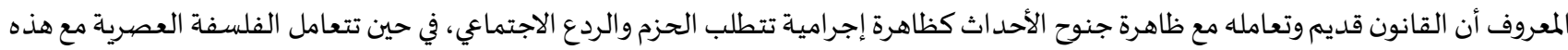

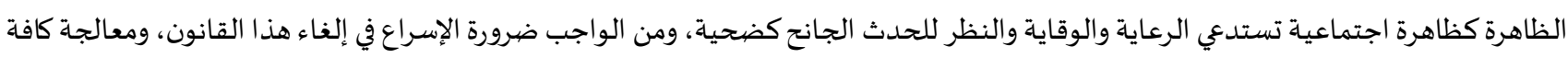

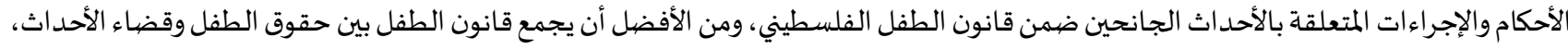

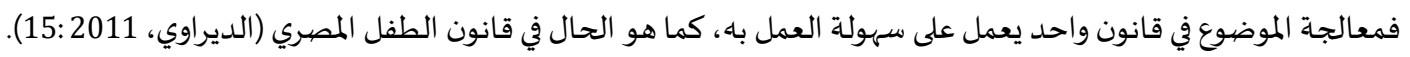

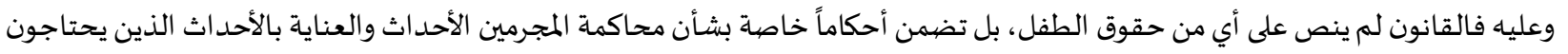

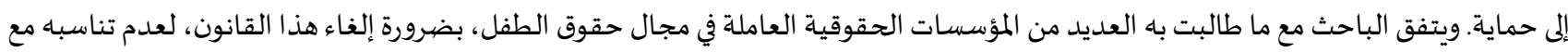
السياسية الجنائية المعاصرة.

المطلب الثاني: قانون إصلاح الأحداث رقم (16) لسنة 1954م:

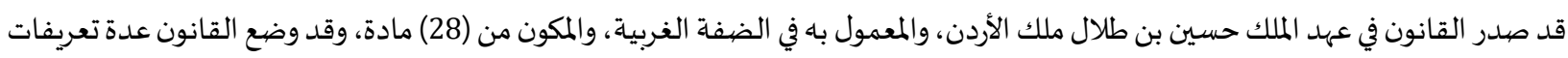

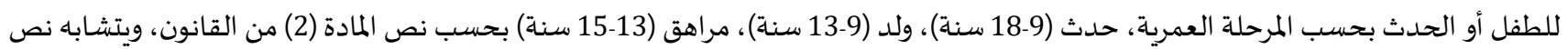

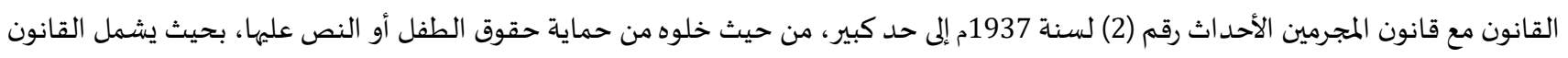

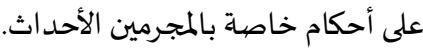

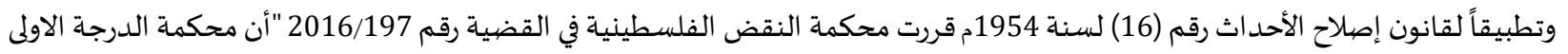

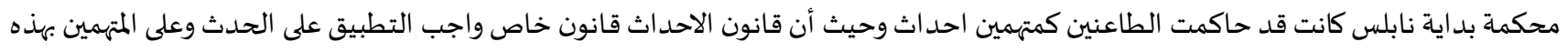

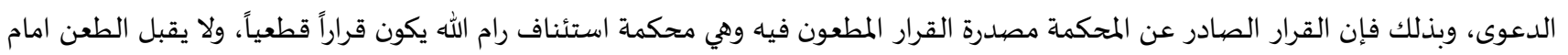

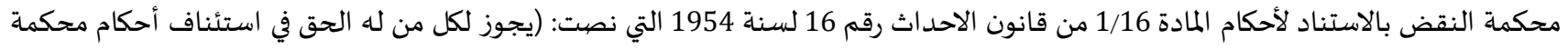

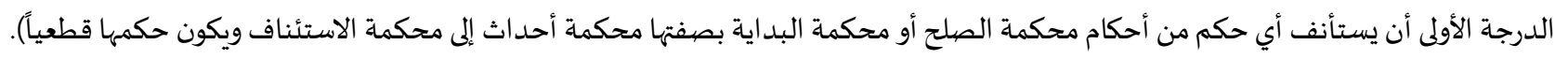

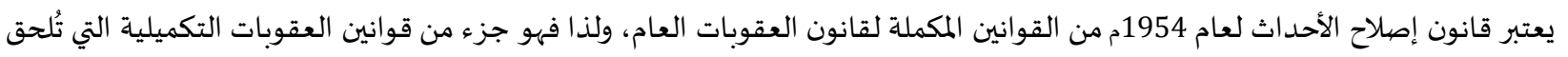

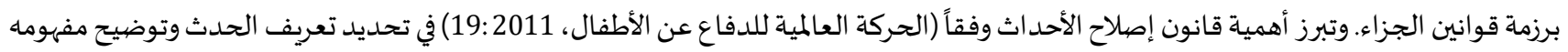

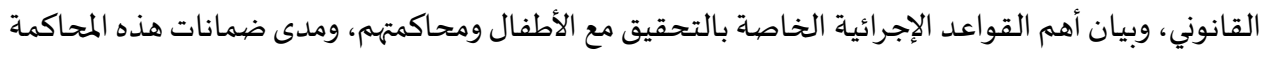

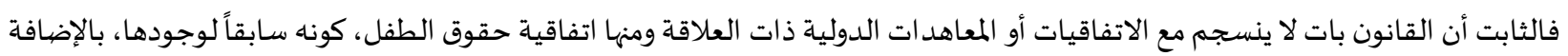

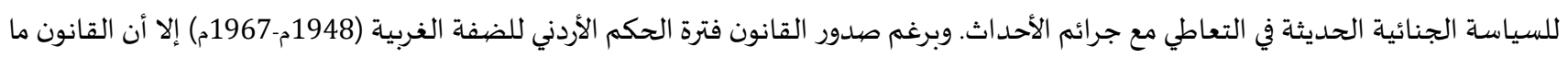

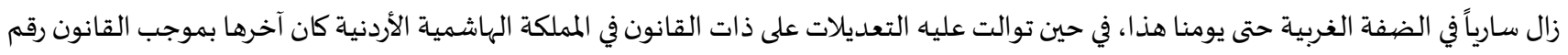

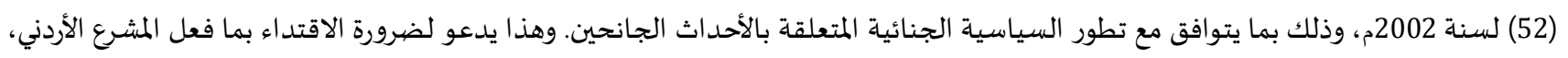

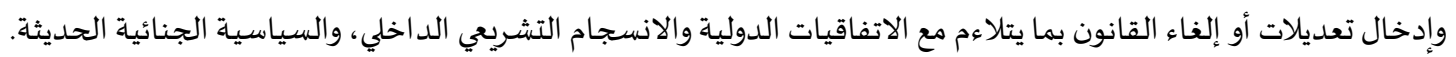

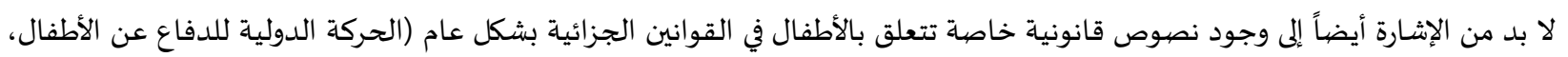

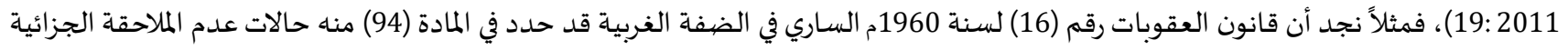

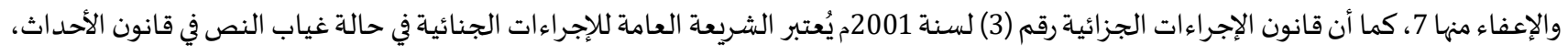

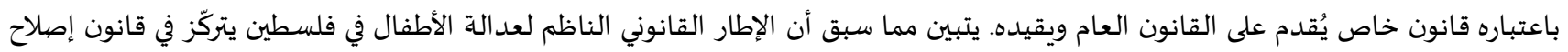
الأحداث رقم (16) لسنة 1954م الساري في الضيفة الغرنية. 
المطلب الثالث: قانون الطفل الفلسطيني رقم (7) لسنة 2004م:

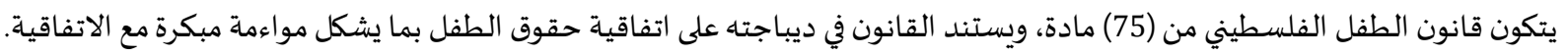

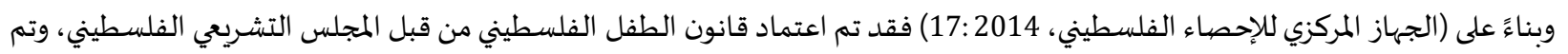

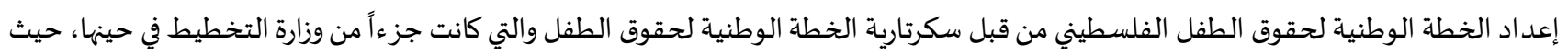

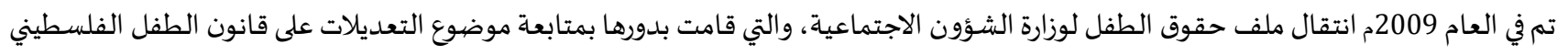

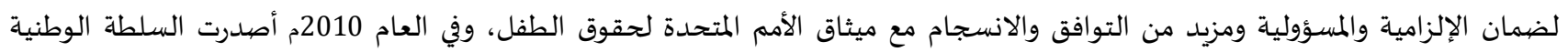

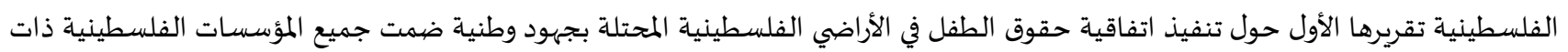

العلاقة.

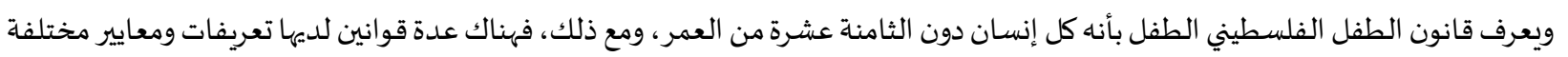

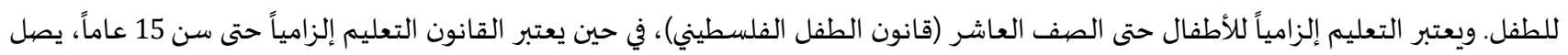

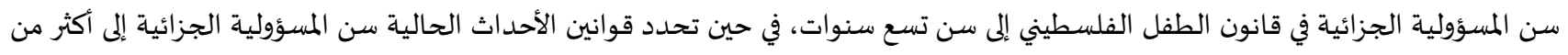

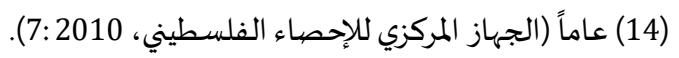

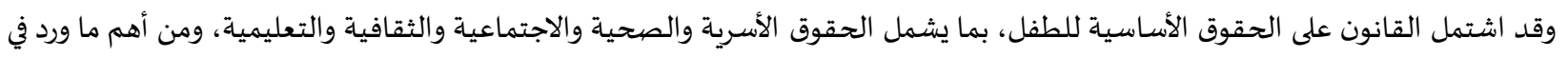

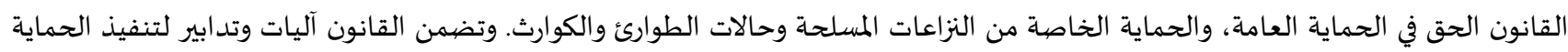

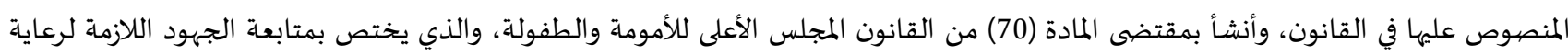
الأمومة والطفولة وحمايتها. كما أفرد القانون فصلاً لمعاملة الأطفال الجانحين، واستبدل بذلك مصطاح المجائل المجرمين الأحداث إلى الأطفال الجانحين، ومنح الأولوية للوسائل

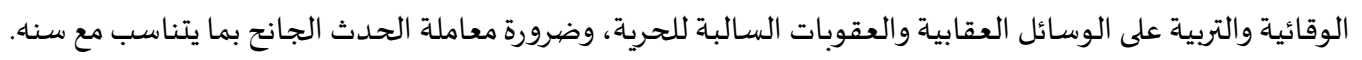

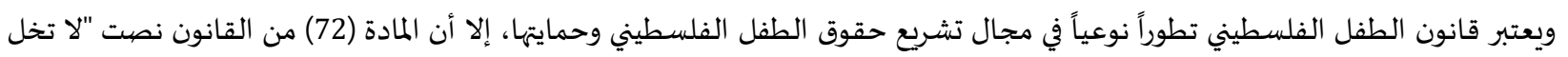

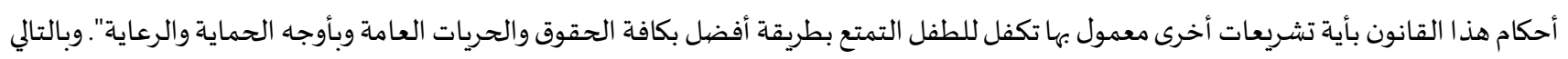

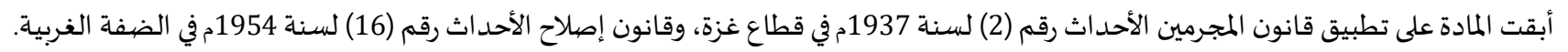

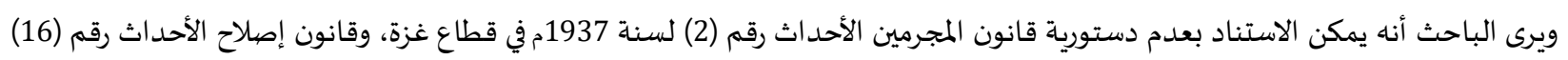

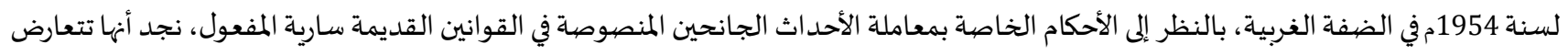

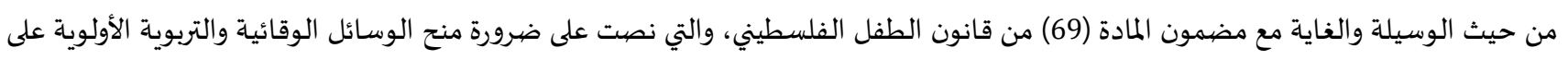

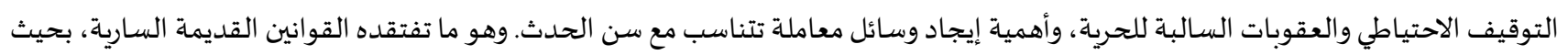

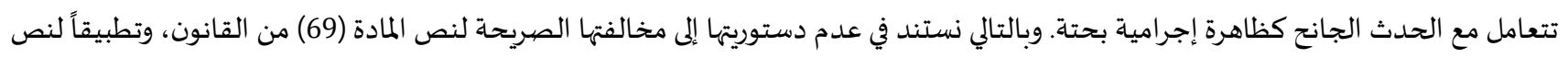

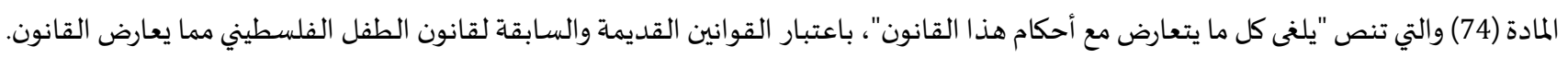

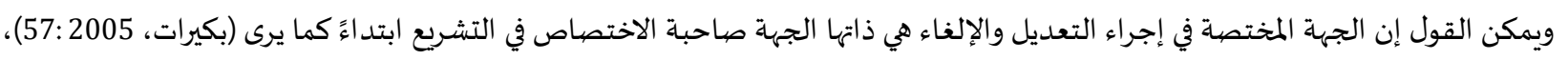

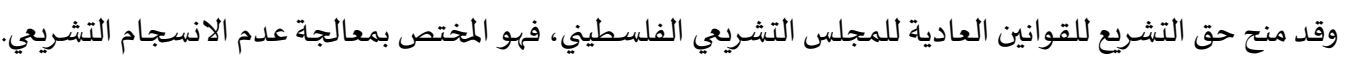

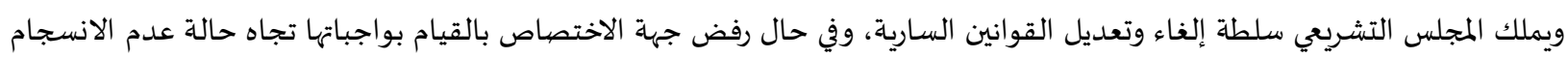

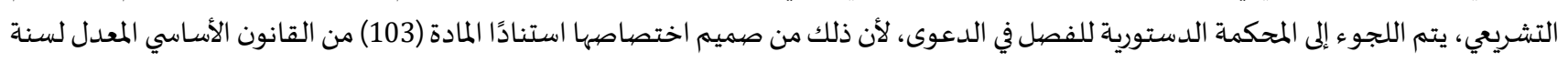

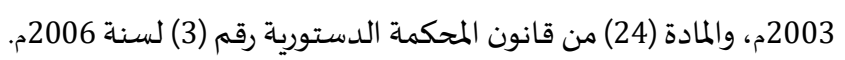

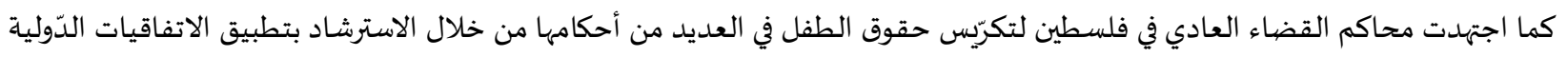

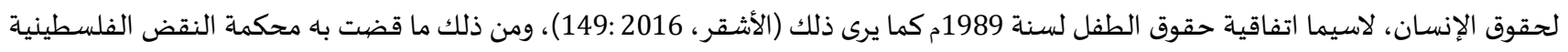

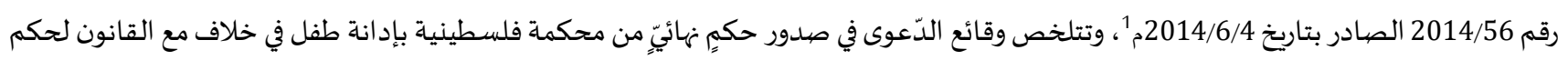

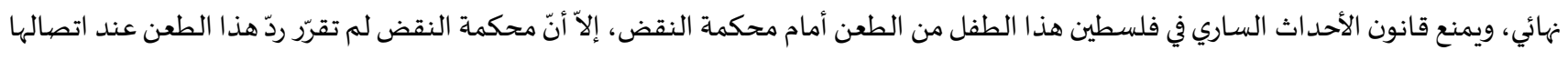

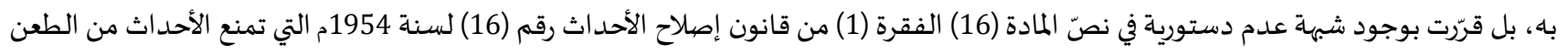

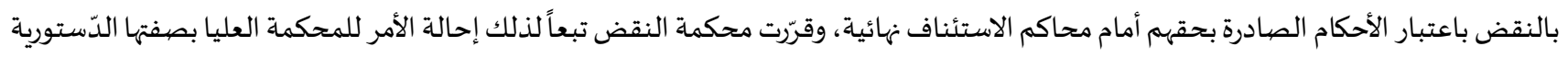

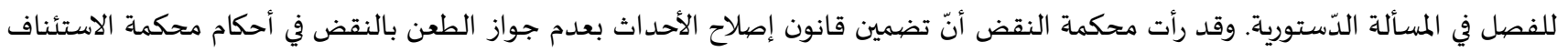

1 
المتصلة بقضايا الأطفال الجانحين باعتبارها أحكاماً قطعية، يمكن أنْ يشكّل مخالفةً دستوريةً لأحكام القانون الأساسيّ الفلسطيني المعدّل لسنة 2003 باعتباره الوثيقة الدّستورية النافذة.

ويعد بذلك قرار محكمة النقض الفلسطينية سابقةً قانونيةً مهمة، بحيث لم يعد يقتصر دور القضاء الوطني في تطبيق الاتفاقية الدولية فحسب، أو الرقابة على تنفيذها بالمعنى الضيق، بل يتعدى ذلك ليكون للقاضي الوطني دوراً في مواءمة التشريعات الوطنية مع الاتفاقيات الدولية وتنفيذ الالتزامات الدولية لانضمام فلسطين للاتفاقيات الدولية. ويوصي الباحث المجلس التشريعي الفلسطيني بضرورة إلغاء القوانين السارية السابقة لقانون الطفل، وتعديل قانون الطفل الفلسطيني بما يجمع كافة الأحكام الخاصةة بحقوق الطفل وحمايتها في قانون واحد. ومواءمة القانون مع الاتفاقية الدولية لحقوق الطفل، والتي جرى انضيمام فلسطين إليها،

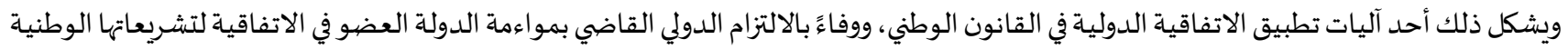
مع الاتفاقية.

\section{المبحث الثاني: قرارات بقو انين بشأن حقوق الطفل في فلسطين}

تعتبر القرارات بقوانين سلطة وسيلة احتياطية بيد السلطة التنفيذية؛ ههدف إلى حماية الدولة والمحافظة على سلامتها من خلال رد الخطر الداهم

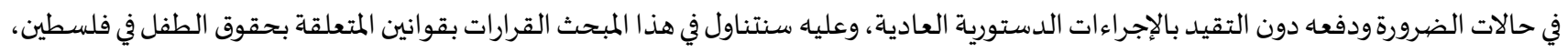
والمعدلة للقوانين آنفة الذكر وتشمل: قرار بقانون رقم (19) لسنة 2012م بشأن تعديل قانون الطفل الفلسطيني، قرار بقانون رقم (4) لسنة 2016م بشأن حماية الأحداث.

المطلب الأول: قراربقانون رقم (19) لسنة 2012م بشأن تعديل قانون الطفل الفلسطيني:

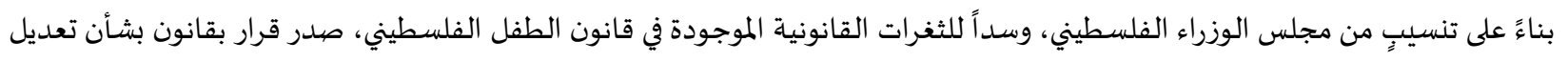
قانون الطفل الفلسطيني، والذي احتوى على تعديل (28) مادة من مواد قانون الطفل الفلسطيني، ويعد تعديل القانون في مجمله تماشياً مع السياساة الجنائية الحديثة وتطويراً للمنظومة القانونية وتعزيزاً لحماية حقوق الطفل، الفول، بحيث شمل التعديل على تحديد العقوبات لانتهاكات حقوق الطفل الواردة في القانون.

وأهم التعديلات التي تضمنها القرار، تعديل المادة (11) من القانون بحيث حظر التعديل إجراء التجارب الطبية والعلمية على الأطفال، وكذلك

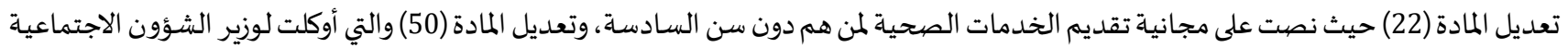
إصدار اللوائح الخاصة بآليات وتدابير واختصاصيات مرشدي حماية الطفولة.

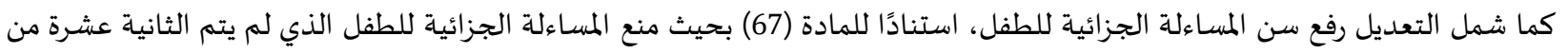

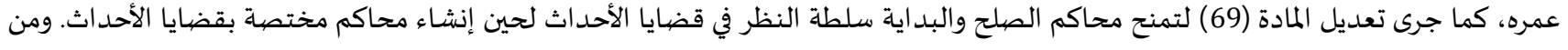
الجدير بذكره أن القرار بقانون أجاز تعديل المادة (70) من القانون لمجلس الوزراء إنشاء المجلس الأعلى للطفل، وتكون لله الشخصية الاعتبارية، وينظم بموجب نظام يصدره مجلس الوزراء، وبذلك يحل المجلس الأعلى للطفل، محل المجلس الأعلى للأمومة والطفولة في فلسطين. وأخيراً فقد منح القرار

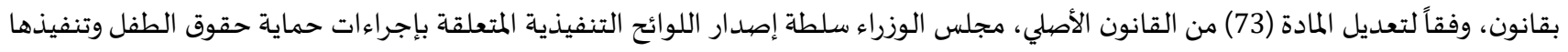
وفقاً لما ورد في القرار بقانون.

المطلب الثاني: قراربقانون رقم (4) لسنة 2016م بشأن حماية الأحداث:

صدر القرار بقانون رقم (4) بشأن حماية الأحداث في عام 2016م، والذي يشكل بدوره أكثر القرارات مسايرة للقوانين الحديثة، ومواءمة مع اتفاقية حقوق الطفل والمواثيق الدولية ذات العلاقة، حيث عرف القرار الحدث "الطفل الذي لم يتجاوز (18) سنة ميلادية كاملة وقت ارتكابه فحلاً مجرماً أو عند وجوده في إحدى حالات التعرض للانحراف" وهو ما يتفق مع تعريف اتفاقية حقوق الطفل، وقانون الطفل الفلسطيني.

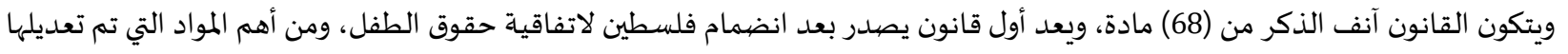

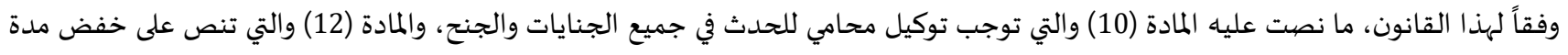

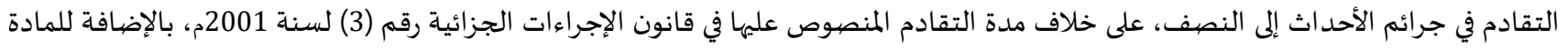

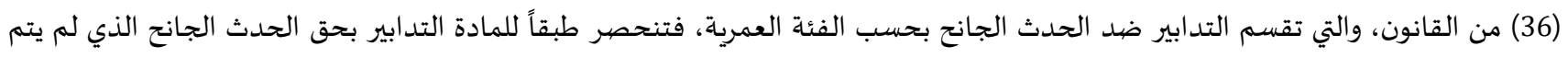
الخامسة عشر من عمره في التوبيخ والتسليم والالحاق بالتدريب المهني والإلزام بواجبات معينة والاختبار القضائي والمراقبة الاجتماعية والإيداع في المشافي 
وقد عدت محكمة استئناف رام الله بصفتها محكمة استئناف قضايا الأحداث في القضية رقم 2018/34 ² أن التدابير الوارد النص علهها في الفصل الرابع من القرار بقانون بشأن حماية الأحداث، إنما هي بحد ذاتها عقوبة يتم ايقاعها على من تقرر الحكم بإدانتها.

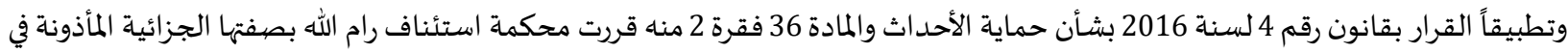
القضية رقم 2018/121 تسليم الحدث لمتولي أمره وإفهامها بضرورة رعايته والعناية باه وتربيته.

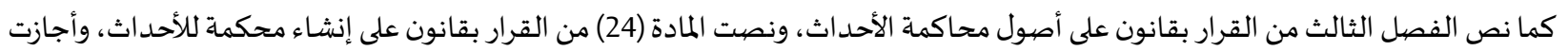

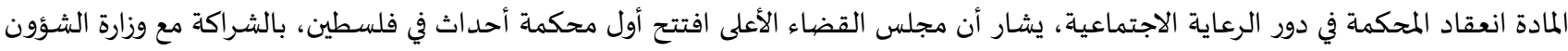

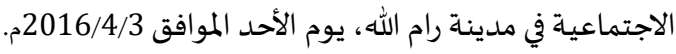

الخاتمة:

ختاماً، فإنه يمكن القول أن قانون الطفل الفلسطيني مع تعديلاته يمثل إضافةً نوعيةً للمنظومة القانونية الفلسطينية، وذلك اعتماداً على

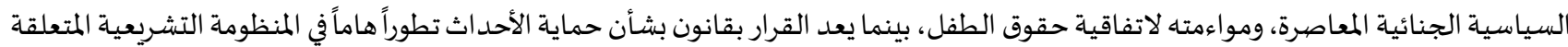

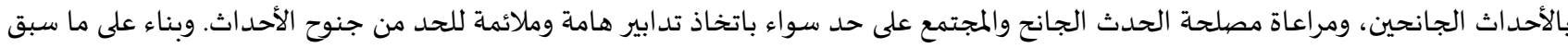

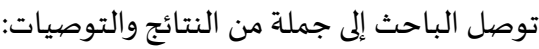

أولًا: النتائج:

1. لما كان قانون المجرمين الأحداث، وقانون إصلاح الأحداث يعتمد على السياسة العقابية القديمة، فلا بد من الإيقاف العمل بهم، واصهدار قوانين

$$
\text { أكثر ملائمة وتماشيًا مع الاتفاقيات الدولية. }
$$

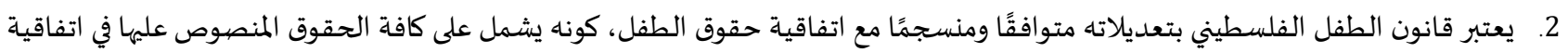
حقوق الطفل باستثناء بعض الحقوق التي نصت عليه الاتفاقية على سبيل التخيير لا الإلزام، مثل إعمال نظام التبني.

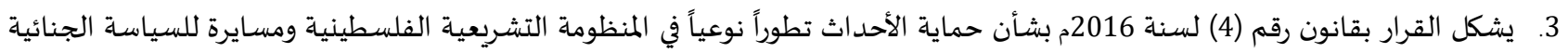
الحديثة، بما جاء باه من إنصاف لحقوق الأحداث وحمايةً لهمه.

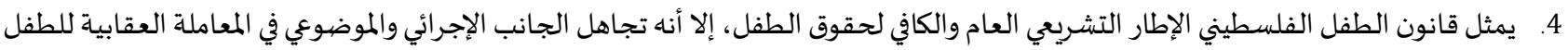
وتركها للقانون القديم؛ لذلك ظهرت حاجة ملحة لتعديل قانون الطفل؛ متضمنًا الجانب الإجرائي والموضوعي في المعاملة العقابية للطفل.

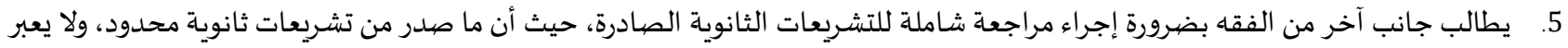
عن حجم هذه الفئة من أفراد المجتمع "53\% من المجتمع الفلسطيني" فمثلاً، لم يضع مجلس الوزراء أية تشريعات ثانوية هامة خاصة باءة بالأطفال

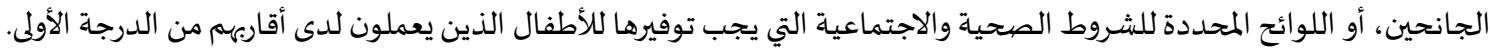
6. لسنة 2004م ، مثل اللائحة التنفيذية المحددة للإجراءات الواجبة الإتباع لتمكين الأطفال من حقهم في الحماية من كافة أشكال العنف، وهذا يدفعنا للتأكيد على أن قانون حقوق الطفل لسنة 2004 هو المحدد الرئيس الذي يجبه التعويل عليهاء من ناحية التطوير. ثانياً: التوصيات: 1. توصي الدراسـة بضرورة إلغاء قانون المجرمين الأحداث رقم (2) لسنة 1937م، وقانون إصلاح الأحداث رقم (16) لسنة 1954م، لعدم صلاحيتهما للتطبيق وعدم مسايرتهما للسياسة الجنائية المعاصرة، وعدم مواءمتهما لاتفاقية حقوق الطفل.

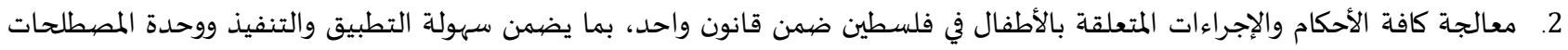
والأحكام على غرار القوانين العربية والغربية الحديثة؛ منعًا للتعارض بين القوانين، ومواكبته لمعايير العداءلة التهاء

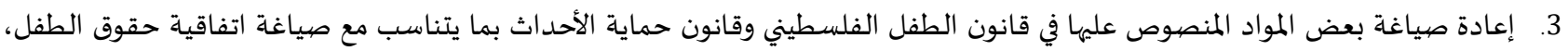
والقيمة القانونية لها، والصفة الإلزامية للالتزامات الناشئة عنها. 


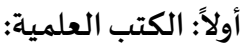
1. الأشقر، أحمد (2016). الاجتهادات القضائية العربية في تطبيق الاتفاقيات الدولية لحقوق الإنسان. معهل حقوق الإنسان والقانون الإنسان.

2. الجهاز المركزي للإحصاء الفلسطيني (2014). واقع حقوق الطفل الفلسطيني. رام الله، فلسطين.

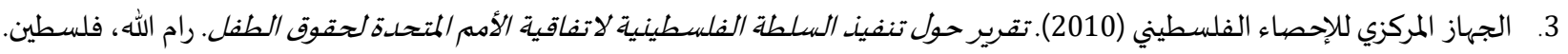

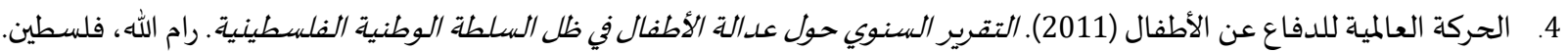
5. الديراوي، طارق (2011). عدالة الأحداث في قطاع غزة. مركز الميزان لحقوق الإنسان، فلسطين.

ثانياً: القو انين والتشريعات:

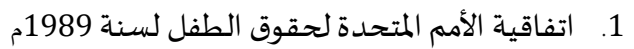

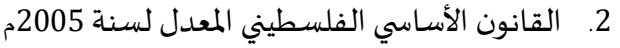

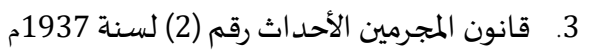

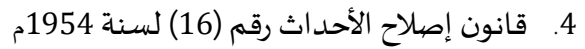
5. قانون الطفل الفلسطيني رقم (7) لسنة 2004 الصانم 6. قرار بقانون رقم (19) لسنة 2012م بشأن تعديل قانون الطفل الفلسطيني 7. 8. قانون المحكمة الدستورية رقم (3) لسنة 2006م.

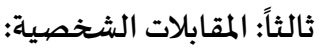

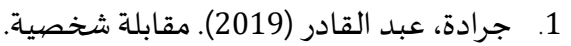
2. الديراوي، طارق (2019). مقابلة شخصية. 3. عبد العاطي، صلاح (2019). مقابلة شخصية.

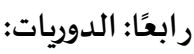

1. بغشام، زقاي (2016). ضهمانات حماية الطفل الجانح أثناء التحقيق. مجلة القانون: 5 (6). 2. بولحية، شهيرة (2018). حقوق الطفل في المواثيق الدولية العامة. مجلة الإحياء: 11 (12018).

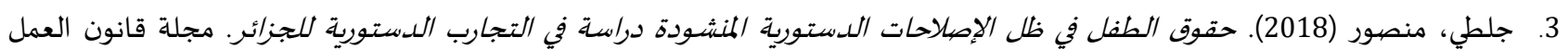
والتشغيل، 3 (5).

4. سيليني، نسيمة (2020). حقوق الطفل في المواثيق والاتفاقيات الدولية وآليات حمايتها. مجلة Academia: 6 (3).

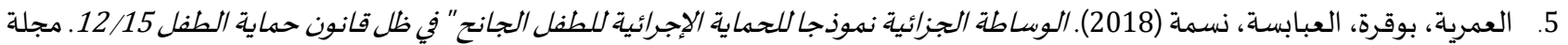

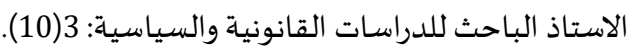

6. العياشي، عنصر (د.ت). اتفاقية حقوق الطفل: دراسة تحليلية وتقويمية لحالة قطر. مجلة الأسرة والمجتمع: 2(2).

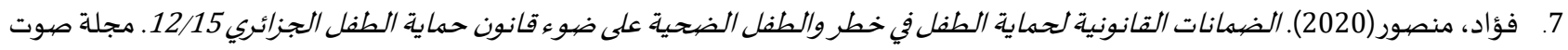

القانون: 7 (2).

8. قسية، محمد (2018). وضع الطفل في حالة خطروآليات حمايته حسب القانون الجزائري لحماية الطفل رقهم 15-12. مجلة التراث: 1(29).

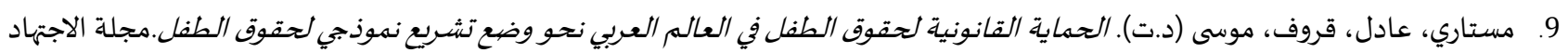

القضائي: $5(7)$ 
www.refaad.com
المجلة الدولية للدراسـات القانونية والفقهية المقارنة

International Journal of Legal and Comparative Jurisprudence Studies (LCJS)

Journal Homepage: https://www.refaad.com/views/LCJS/Home.aspx

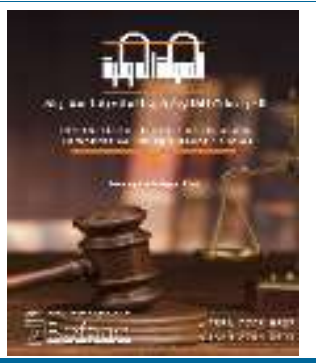

\title{
Legal regulation of children's rights in Palestinian legislations
}

\author{
Ahmad A. Shehab \\ Lecturer at Faculty of Sharia and law, Islamic University in Gaza, IUG. Palestine \\ ashehab@iugaza.edu.ps
}

Received: 18/10/2020 Revised: 25/1/2021 Accepted: 17/3/2021 DOI: https://doi.org/10.31559/LCJS2021.2.1.1

\begin{abstract}
The study aims to analyze and evaluate the legal regulation of the rights of the child in Palestinian legislation, as it sheds light on the extent to which Palestinian legislation harmonizes the rights of the child with their own international convention and its applicability, and given the importance of the subject of study considering that international conventions are a main source of international law and are binding on signatory states. The problem of the study on the validity of Palestinian legislation related to children for implementation and evaluation, and the study of the amendments that have been made to it in accordance with the contemporary criminal policy and development in the global legislative system. In order to achieve the main objective of the study, the researcher used the descriptive and analytical approach, by analyzing legal texts and extrapolating the jurisprudential opinions and judicial rulings. The researcher also adopted a personal interview as a tool for collecting information and enriching the subject of the study. 2) For the year 1937 AD, and the Juvenile Reform Law No. 16 (for the year 1954 AD), due to their lack of validity for implementation, their inconsistency with contemporary criminal policy, their inconsistency with the Convention on the Rights of the Child, and treating all provisions and procedures related to children in Palestine within one law, in a manner that ensures ease of application and implementation
\end{abstract}

Keywords: children's rights; legislation; Palestine.

\section{References:}

1. Al'mryh, Bwqrh, Al'babsh, Nsmh (2018). Alwsath Aljza'yh Nmwdja Llhmayh Alejra'yh Lltfl Aljanh " Fy Zl Qanwn Hmayh Altfl 15/ 12. Mjlt Alastad Albahth Lldrasat Alqanwnyh Walsyasyh: 3(10).

2. Al'yashy, 'nsr (D.T). Atfaqyh Hqwq Altfl: Drash Thlylyh Wtqwymyh Lhalt Qtr. Mjlt Alasrh Walmjtm': 2(2).

3. Bghsham, Zqay (2016). Dmanat Hmayh Altfl Aljanh Athna' Althqyq. Mjlt Alqanwn: 5(6).

4. Bwlhyh, Shhyrh (2018). Hqwq Altfl Fy Almwathyq Aldwlyh Al'amh. Mjlt Alehya': 11 (13).

5. F'ad, Mnswr (2020). Aldmanat Alqanwnyh Lhmayh Altfl Fy Khtr Waltfl Aldhyh 'la Dw' Qanwn Hmayh Altfl Aljza'ry 15/12. Mjlt Swt Alqanwn: 7(2).

6. Jlty, Mnswr (2018). Hqwq Altfl Fy Zl Aleslahat Aldstwryh Almnshwdh Drash Fy Altjarb Aldstwryh Lljza'r. Mjlt Qanwn Al'ml Waltshghyl, 3(5).

7. Mstary, 'adl, Qrwf, Mwsa (D.T). Alhmayh Alqanwnyh Lhqwq Altfl Fy Al'alm Al'rby Nhw Wd' Tshry' Nmwdjy Lhqwq Altfl. Mjlt Alajthad Alqda'y: 5(7).

8. Qsyh, Mhmd (2018). Wd' Altfl Fy Halt Khtr Walyat Hmayth Hsb Alqanwn Aljza'ry Lhmayh Altfl Rqm 15-12. Mjlt Altrath: $1(29)$.

9. Sylyny, Nsymh (2020). Hqwq Altfl Fy Almwathyq Walatfaqyat Aldwlyh Walyat Hmaytha. Mjlt Academia: 6(3). 